\title{
Extremity Soft Tissue Sarcoma Mimicking Traumatic Intramuscular Hematoma: A Case Report and Review of The Literature
}

\author{
Yu De Su and Po Yin Shen* \\ Department of Orthopedics, Kaohsiung, Taiwan \\ *Corresponding author: Po Yin Shen, Department of Orthopedics, Kaohsiung, Taiwan
}

\begin{tabular}{|c|c|}
\hline ARTICLE INFO & ABSTRACT \\
\hline Received: 彗 March 30, 2019 & \\
\hline Published: April 10, 2019 & $\begin{array}{l}\text { Background: Soft tissue sarcoma can be mimicked as intramuscular hematoma in rare } \\
\text { cases. We report one patient with rhabdomyosarcoma mimicking traumatic intramuscular } \\
\text { hematoma. }\end{array}$ \\
\hline $\begin{array}{l}\text { Citation: Yu De Su, Po Yin Shen. Ex- } \\
\text { tremity Soft Tissue Sarcoma Mim- } \\
\text { icking Traumatic Intramuscular } \\
\text { Hematoma: A Case Report and Re- } \\
\text { view of The Literature. Biomed J } \\
\text { Sci \& Tech Res 16(5)-2019. BJSTR. } \\
\text { MS.ID.002927. }\end{array}$ & $\begin{array}{l}\text { Case report: A } 60 \text {-year-old patient had an episode of minor trauma to the lower } \\
\text { limb. Initial clinical and image findings interpreted the swelling lump as intramuscular } \\
\text { hematoma. Few months later, the lesion increased significantly with time and pain got } \\
\text { worsened. After serial MRI exams, needle biopsy, and surgical resection, the final result } \\
\text { showed pleomorphic rhabdomyosarcoma. Discussion: Soft tissue sarcoma mimicking } \\
\text { traumatic intramuscular hematomas in the extremity has rarely been reported in the } \\
\text { literature. Chronic expanding hematoma over soft tissue can manifest as a space-occupying }\end{array}$ \\
\hline $\begin{array}{l}\text { Keywords: Sarcoma; Hematoma; Bi- } \\
\text { opsy; Magnetic resonance imaging }\end{array}$ & $\begin{array}{l}\text { lesion which mimics a sarcoma. To make accurate diagnosis will be challenging for the } \\
\text { clinician. It is important to evaluate prior trauma history, perform serial images and even } \\
\text { biopsy with an unusual presentation of traumatic hematoma in the extremities. MRI is an }\end{array}$ \\
\hline $\begin{array}{l}\text { Abbreviations: Nuclear Magnetic Res- } \\
\text { onance Imaging (MRI) }\end{array}$ & $\begin{array}{l}\text { important diagnostic tool, but if any doubt, serial MRI and biopsy can help to avoid tragic } \\
\text { consequences of missed soft tissue sarcoma. Conclusion: It may be difficult to differentiate } \\
\text { soft tissue sarcoma from traumatic intramuscular hematoma due to similarities in clinical } \\
\text { presentation and image characteristic. Careful history taking, serial MRI, and biopsy can } \\
\text { help to make more accurate diagnosis. }\end{array}$ \\
\hline
\end{tabular}

\section{Introduction}

The management of large intramuscular hematoma in the extremities is sometimes difficult, especially when there is no clear etiology. It can be spontaneous or secondary to trauma, bleeding disorders, tumor, or recent surgery in clinical practice [1,2]. Patients usually complain pain, swelling, and frequent ecchymosis over the involved area after trauma. However, if a patient presents with an expanding traumatic hemorrhagic mass without bleeding disorder or bruise, several differential diagnoses should be considered including chronic expanding hematoma, aneurysm, abscess, and soft tissue sarcoma. Undetected sarcoma will cause catastrophic result. Dealing with these cases are quite challenging since both the intramuscular hematoma and soft tissue sarcoma share the similar clinical symptoms and imaging findings.

\section{Case Report}

A 60-year old female kicked on the motor vehicle with the right lower extremity and developed mild pain at the right calf in September 2017. Five months later, without improvement in her symptoms and persistent swelling in the lateral aspect of calf, she came to the out-patient department (OPD) in Kaohsiung Medical University Hospital. Physical exam revealed pain to palpitation and slight swelling of right lateral calf. Based on the trauma history with no other specific findings, the physician diagnosed a muscle sprain with concomitant bleeding and treated her with pain medication. For further survey of prolonged leg swelling, an MRI was obtained weeks later that showed multilobulated mass (about $16 \times 4 \mathrm{~cm}$ ) in anterior tibialis muscle, heterogeneous signal intensity on both T1 
and T2 weighted images. Both the radiologist and the attending physician interpreted the MRI as intramuscular hematoma with multiple stages. So conservative care with continued physical therapy was recommended. Three months later, the mass continued to increase in size and symptoms became worsened. The patient visited our OPD again and was thus referred to the Orthopedic oncology surgeon for evaluation. Clinical exam showed a $18 \mathrm{x}$ $4.5 \mathrm{~cm}$, firm, irregular, immobile mass extending from the anterior to the lateral aspect of right calf (Figure 1).

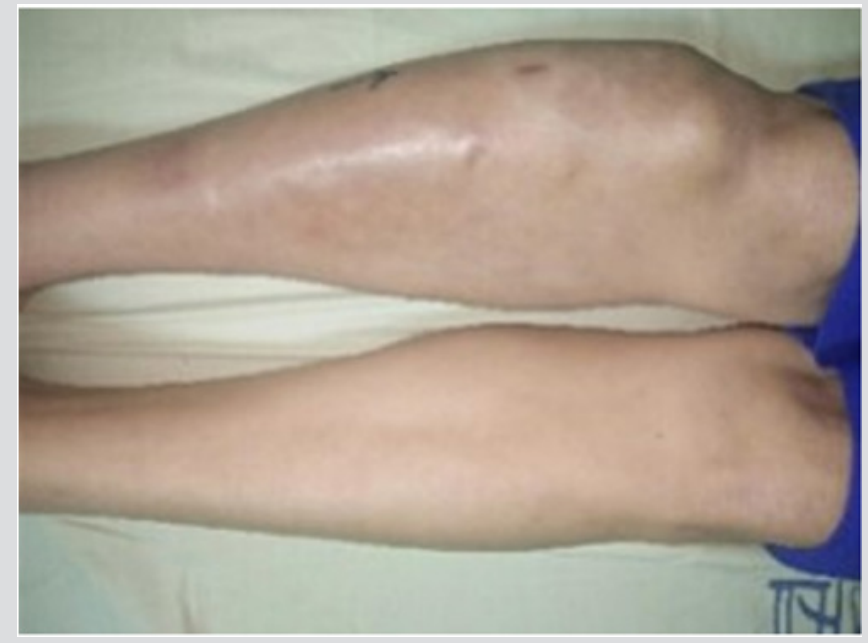

Figure 1: Photograph of the right tibia before surgery. Right calf is severely swelling.

There was no numbness or weakness or sensory defect in the affected lower limb. Laboratory data including bleeding time and blood coagulation was normal. Fine needle biopsy was carried out, and the analysis proved the fresh with old unclotted blood. Due to symptoms progression, a repeat MRI was performed. The finding reported by the radiologist revealed as increasing size $(20 \times 5 \mathrm{~cm})$ of intramuscular hemorrhagic lesion in anterior tibialis, with involvement of pretibial fascia and cortex destruction at the proximal tibia (Figure 2), with high possibility of malignancy. Angiography also revealed a highly vascularized mass with malignancy characteristic. Due to the high possibility of malignancy, she underwent wild excision of the tumor on May
2018. At the surgery, a large encapsulated mass containing thick gelatinous gray material was found (Figure 3), involving pretibial fascia as well as the lateral and posterior component of the calf. The resected specimen was sent for frozen pathology and demonstrated highly suspect myosarcoma. It revealed the undifferentiated, spindle to multinucleated polygonal neoplastic cell with abundant of eosinophilic cytoplasm. The final histopathology revealed pleomorphic rhabdomyosarcoma. After the surgery, the pain resolved significantly. The patient received adjuvant radiation therapy. The recovery was good. No lung metastasis was found at the time this report was made.
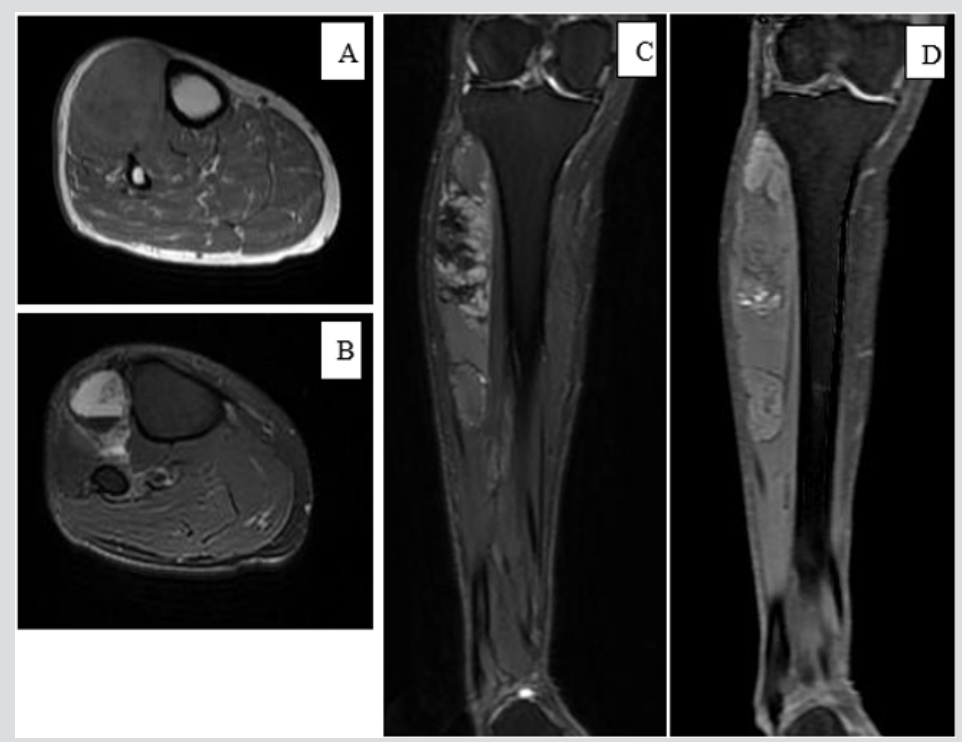

Note: A 60-year-old female developed a painful lump at the anterolateral side of calf after minor trauma. MRI revealed intramuscular hematoma with multiple stage and no evidence of bone and fascia invasion.

Figure 2a: (First MRI, A: axial T1-weighted, B: axial T2-weighted, C: coronal T1-weighted, D: coronal T2-weighted). 


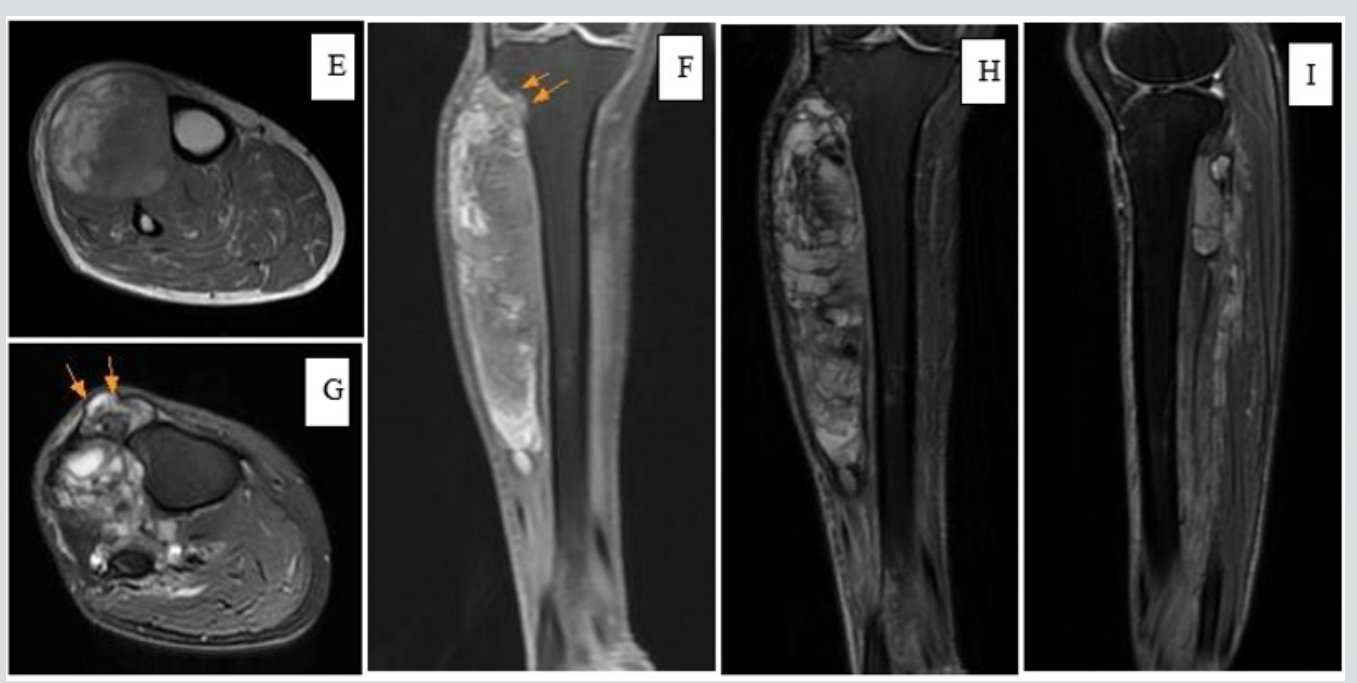

Figure 2b: (Second MRI, E: coronal T1-weighted, F: axial T1-weighted, G: axial T2-weighted+FS, H: coronal T2-weighted +FS, I: sagittal T2-weighted+FS).

(E, F)- an increased size of intramuscular mass with a mix of iso-to-high signal

intensity in the anterolateral aspect of calf. Two arrows indicate cortical destruction at the proximal lateral tibia (not seen in the first MRI)

(G)- tumor invasion with pretibial fascia involvement (two arrows) (not seen in the first MRI)

$(\mathrm{H}, \mathrm{I})$ - an increased mass size with heterogeneously distributed iso-to-high signal intensity in the anterior, lateral, and posterior aspect of calf.

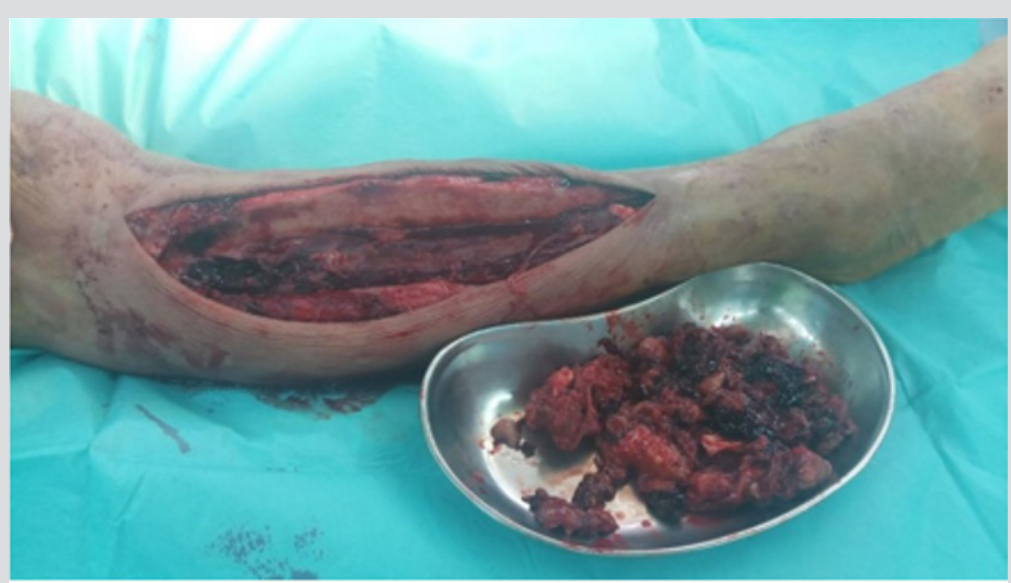

Figure 3: The speciman showing encapsuled, blood liquid and thick coagulated mass.

\section{Discussion}

Soft tissue sarcoma accounts for about $1 \%$ of adult malignancy. It usually presents as a painless lump and can occur at any site over the whole body. Almost $45 \%$ of the soft tissue sarcoma appears adjacent to the long bone of the extremities, especially in the lower limb [1]. However, few people know that soft tissue sarcoma occasionally accompanies large hematoma [2]. In certain situation, soft tissue sarcoma may be initially misdiagnosed as deep intramuscular hematoma. Clinicians should be aware of the possibility of soft tissue sarcoma masquerading hematoma after trauma. MRI is a powerful tool for diagnosing soft tissue masses due to high contrast tissue resolution [3]. It remains the gold standard to distinguish the soft tissue tumor from hematoma. The hematoma revealed various signal intensity at difference stages [4]. Acute hematoma shows low-to-intermediate signal intensity on T1 weighted image (T1WI) and high signal on T2 weighted image (T2WI) [5]. In the following days, the hematoma may appear intermediate signal intensity in T2WI. Chronic hematomas are usually surrounded by the fibrous capsule demonstrating hypointensity in both T1 and T2 weighted images.

Mixture of heterogeneous signal may occur in recurrent blooding event as a result of blood products in different metabolic stage. For the soft tissue sarcoma, it generally contains a solid component which often reveals iso-hypo intensity to muscle on T1WI and heterogeneous hyperintensity on T2WI [6]. However, variation in image finding are occasionally observed. Contrast- 
enhanced MRI is helpful but overlapping of features will lead to uncertainty. For instance, diagnosis can be challenging if large portion of the tumor is occupied by hematoma without a solid mass lesion on the MRI [7]. Ogose et al. [8] reported an extra-skeletal Ewing sarcoma mimicking a traumatic hematoma in a 16-year old baseball player with a history of recurrent hematoma of the thigh. Therefore, a detailed survey of each patient's history, clinical course, and radiography including MRI plays an important role in making differential diagnosis. After reviewing current studies, we concluded that the soft tissue sarcoma mimicking as hematoma should be considered in the following situation:

a) The lesion doesn't correlate with the expected clinical course of blood clot degeneration. If the hematoma enlarges or pain deteriorates, malignancy should be warranted.

b) If the large intramuscular hematoma presents, and the patient denied bleeding disorder and prior trauma, soft tissue sarcoma should be highly suspected.

c) In chronic hematoma with peripheral wall enhancement on T2WI, awareness should be raised because its appearance is much more likely a sarcomatous lesion [1].

d) The mechanism of the injury reveals disproportion with clinical severity such as pain, swelling, and functional disability [9].

e) Traumatic hemorrhage usually causes subcutaneous ecchymosis, while intratumoral hemorrhage often is constrained by a pseudo capsule and less likely to have ecchymosis [10].

In complicated cases, it poses great challenges for clinician in making correct diagnosis after history taking, physical examination, and initial radiographic assessment. Biopsy are recommended and can provide more information for making diagnosis. Fine need aspiration was traditionally considered a useful method for the diagnosis of bone and soft-tissue tumor. Nonetheless, in sarcomarelated hematoma, it involves the risk of sample error and yields very low diagnostic accuracy because of insufficient tumor cells from aspiration. Imaizumi, reported six cases with soft tissue sarcoma that were initially diagnosed as traumatic hematoma. In five of the patients, the cytology revealed no malignant cell. In our case, the report for fine needle biopsy also showed negative for malignant cell. For entities of unknown aggressiveness that may represent a sarcoma, core needle or open biopsy is preferable and has higher diagnostic accuracy. In most published studies, MRI was performed only once before preceding to the biopsy and surgery. We recommended to repeat MRI before the next procedure. It might be helpful to detect the changes of focal lesion. In our case, the first MRI was not in favor of malignant tumor. Several months later, a repeat MRI showed high possibility of malignant tumor. We propose that repeat MRI before biopsy and surgery may be beneficial to provide more information to make differential diagnosis.

\section{Conclusion}

If a patient presents with expanding traumatic intramuscular hematoma, several differential diagnosis should be considered including soft tissue sarcoma. Careful investigation of trauma mechanism, clinical symptoms, and MRI findings are helpful to avoid misdiagnosis. Repeat MRI may provide more information on the new development or elapse of the soft tissue mass and reevaluate the possibility of soft tissue tumor mimicking hematoma. Core needle or open biopsy can be helpful to make more accurate diagnosis and treatment.

\section{Acknowledgement}

Yu-De, Su carried out the patient database and drafted the manuscript. Po-Yin, Shen, conceived of the study and helped to draft the manuscript.

\section{References}

1. Shyam K, Cicilet S, Philip B (2018) Among the fibers: A multimodality imaging review of intramuscular mass lesions. Indian J Radiol Imaging 28(2): 214-224

2. Hoshi M, Oebisu N, Ieguchi M, Ban Y, Takami M, et al. (2017) Clinical features of soft tissue sarcoma presenting intra-tumour haematoma: case series and review of the literature. International Orthopaedics (SICOT) 41(1): 203-209.

3. Taïeb S, Penel N, Vanseymortier L, Ceugnart L (2009) Soft tissue sarcomas or intramuscular haematomas? European Journal of Radiology. 72(1): 44-49.

4. Imaizumi S, Morita T, Ogose A, Hotta T, Kobayashi H, et al. (2002) Soft tissue sarcoma mimicking choronic hematoma: value of magnetic resonance imaging in differential diagnosis. J Orthop Sci 7(1): 33-37.

5. Niimi R, Matsumine A, Kusuzaki K, Okamura A, Matsubara T, et al. (2006) Soft-tissue sarcoma mimicking large haematoma: a report of two cases and review of the literature. Journal of Orthopaedic Surgery 14(1): 9095.

6. Kontogeorgakos VA, Martinez S, Dodd L, Brigman BE (2010) Extremity soft tissue sarcomas presented as hematomas. Arch Orthop Trauma Surg 130(10): 1209-1214

7. Muniandy M, Singh VA (2009) Can a chronic expanding haematoma mimic a soft tissue sarcoma? BMJ Case Rep. bcr 09.2008.0846.

8. Ogose A, Hotta T, Yamamura S, Shioya Y, Yazawa T, et al. (1998) Extraskeletal Ewing's sarcoma mimicking traumatic hematoma. Arch Ortho Trauma Surg 118(3): 172-173.

9. Gomez P, Morcuende J (2004) High-Grade Sarcomas Mimicking Traumatic Intramuscular Hematomas: A Report of Three Cases. Iowa Orthop J 24: 106-110.

10. Ward WG Sr, Rougraff B, Quinn R, Damron T, O'Connor MI, et al. (2007) Tumors masquerading as hematomas. Clin Orthop Relat Res 465: 232240. 


\section{ISSN: 2574-1241}

DOI: 10.26717/BJSTR.2019.16.002927

Po Yin Shen. Biomed J Sci \& Tech Res

(c) (P) This work is licensed under Creative

Submission Link: https://biomedres.us/submit-manuscript.php

$\begin{array}{ll}\text { BIOMEDICAL } & \text { Assets of Publishing with us } \\ \text { RESEARCHES } & \text { - Global archiving of articles } \\ \text { - Immediate, unrestricted online access }\end{array}$

